
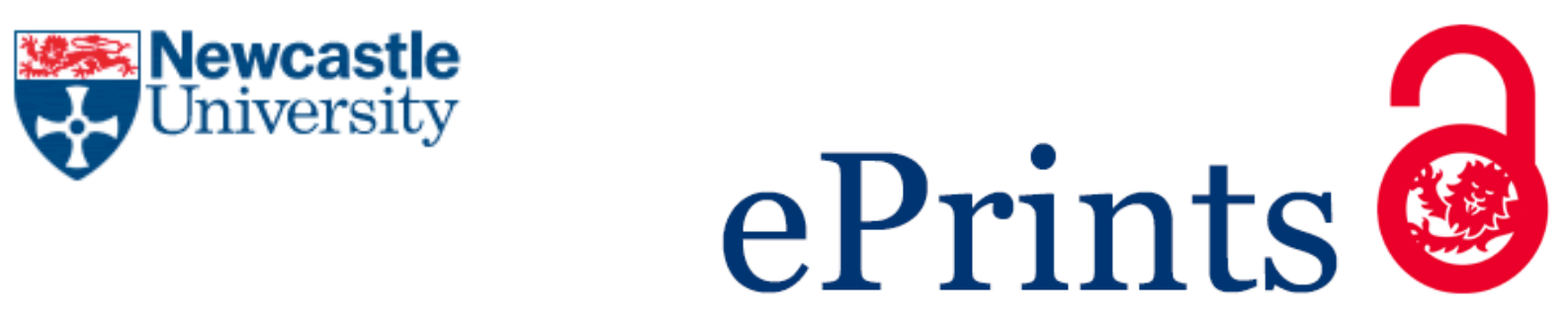

Papagiannidis S, See-To E, Assimakopoulos D, Yang Y.

Identifying industrial clusters with a novel big-data methodology: are SIC codes (not) fit for purpose in the Internet age?.

Computers \& Operations Research 2017,

https://doi.org/10.1016/j.cor.2017.06.010

\title{
Copyright:
}

(C) 2017. This manuscript version is made available under the CC-BY-NC-ND 4.0 license

DOI link to article:

https://doi.org/10.1016/i.cor.2017.06.010

Date deposited:

$13 / 06 / 2017$

Embargo release date:

21 December 2018

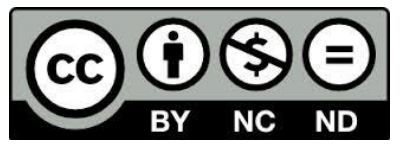

This work is licensed under a

Creative Commons Attribution-NonCommercial-NoDerivatives 4.0 International licence 


\title{
Identifying industrial clusters with a novel big-data methodology: are SIC codes (not) fit for purpose in the Internet age?
}

\begin{abstract}
In this paper we propose using a novel big-data data-mining methodology and the Internet as a new source of useful meta-data for industry classification. The proposed methodology can be utilised as a decision support system for identifying industrial clusters in almost real time in a specific geographic region, contributing to strategic co-operation and policy development for operations and supply chain management across organisational boundaries through big data analytics. Our theoretical discussion on discerning industrial activity of firms in geographical regions starts by highlighting the limitations of the Standard Industrial Classification (SIC) codes. This discussion is followed by the proposed methodology, which has three main steps revolving around web-based data collection, pre-processing and analysis, and reporting of clusters. We discuss each step in detail, presenting the experimental approaches tested. We apply our methodology to a regional case, in the North East of England, in order to demonstrate how such a big data decision support system / analytics can work in practice. Implications for theory, policy and practice are discussed, as well as potential avenues for further research.
\end{abstract}

Keywords: industry classification, SIC codes, big data analytics, clusters, operations, strategic co-operation, regional policy, North East of England 


\section{Identifying industrial clusters with a novel big-data methodology: are SIC codes (not) fit for purpose in the Internet age?}

\section{Introduction}

The Internet and emerging web crawler technologies, coupled with real time big data, open up great opportunities for all kinds of novel decision support systems, enabling strategy and policy initiatives at the regional or/and cross regional levels. Industrial clustering research has a long lineage in economic theory, as well as social and economic policy and practice [1-9]. However, the available methodologies from information science and regional economic geography have not yet reached the level of integration needed to facilitate the study of phenomena such as the formation (or dissolution) of geographical clusters over time based on the Internet and web search related big data. Moreover, the use of Standard Industry Classification (SIC) codes seems increasingly outdated.

A pertinent research question is therefore whether the Internet and modern analytical techniques, such as big data analytics, can be used as a source of knowledge for cluster studies and strategic co-operation and policy development across organisational boundaries. Or, put differently, can we use the Internet for identifying clusters and related industrial activities upstream or downstream of a particular supply chain, complementing, but potentially also extending, the scope of the Standard Industry Classification (SIC) codes? One major challenge in supply chain management and operation management to leverage from big data is the analytical difficulties in understanding and extracting valuable knowledge from huge volumes of data, and this knowledge can then be used for enhancing the performance of many different processes for organizations and throughout the supply chain. There is huge untapped potential for valuable knowledge generation from big data analytics for organizational and supply chain process improvement [10]. Using the Internet as the vast data repository it is or a conduit for connecting data sets offers an opportunity to get a more representative and detailed view of economic activities. At the same time the ability to regularly undertake the analysis and reporting and to have clusters emerge in an ab initio manner are major advantages compared to the existing approaches. In tackling such a challenge, we aim to contribute to the emerging body of literature on collaborative supply chain analytics which is situated at the strategic level, in which an organisation collaborates with external business partners to perform supply chain operations [11]. Using web site data to cluster companies is a first step towards paving the way to capturing the operational activities and interactions among company and clusters in a more granular manner. Still it can offer valuable insights from a policy perspective when it comes to encouraging regional collaborations and facilitating supply and value chain development.

Regional innovation and competitiveness for small and large firms alike is dependent on clusters, fostering learning and innovation across different organisational settings and all sorts of boundaries. Currently, as key enabling technologies require an increasing complexity of collaboration and networking, clusters become even more important for increasing the speed of innovation and distributing the risks and costs associated with emerging technological 
developments [12]. As hotbeds for entrepreneurship and innovation, clusters nurture growing ecosystems of talent, expertise and investments for germinating emerging technologies for medium and high velocity markets locally, but also across large geographical distances. Digitally enabled technologies and web based services are becoming part of a distributed network architecture that is affected by such clustering of businesses, which in turn drives further development across local and global geographical distances. This can be of special importance for supply chain management managers, who need to pay attention to the diverse methodologies and techniques in order to harvest the benefits from big data in their organisations and supply chains and in particular how they can be integrated with other business activities [11].

In contrast to a significant and growing body of literature in cluster studies there is very little known about how the Internet and web meta-information describing industrial activities can become an advantageous complementary source of big-data for detecting clusters (e.g. see [13-15]). The use of the Internet as an information resource to undertake or augment regional scale industrial cluster type studies is relatively new [16]. Many potential users seeking to gain knowledge about companies by using the Internet in a similar context are driven by the possibilities for commercial market opportunities, rather than basic research, and similarly they may also seek to gain knowledge on the firm as an aid to competitor analysis. There is, however, a growing number of researchers from information science, who have developed methods for large scale information retrieval via 'web crawlers' [17-21]. The researchers in this field are often from a computing science, artificial intelligence, or machine learning background and are often following lines of enquiry primarily in one or more of these areas, with the examination of some specific economic activity being undertaken only on an infrequent basis and usually to demonstrate the efficacy of some particular line of development rather than as an end in itself. In order to help address this literature gap, our paper presents a novel methodology that draws on both information science and cluster studies. Our research objective is to advance and test a systematic approach for detecting new "codes" or SIC related categories of industrial activities. Our methodology leverages on recent advances in clustering analysis with unstructured text data, while extant research on clustering algorithms has been mostly focused on structured, quantitative data (e.g. [22, 23]).

The paper is divided into five additional sections discussing, first, the justification for our research (including the limitations of SICs for cluster studies), our theoretical and methodological frameworks, presenting some illustrative findings from a region that is used for testing purposes

and drawing our main conclusions and implications for policy and practice, as well as offering avenues for further research.

\section{Literature Review}

\subsection{Industrial districts and geographical clusters though the lens of SIC}

After Alfred Marshall [24] studied the emerging steel industry in Sheffield and cotton industry in Bradford at the beginning of the industrial revolution, a number of commentators 
looked at the effect of agglomeration and industrial location theory [25, 26]. External economies, i.e. economic benefits not generated within the firm, were propounded by Marshall as having a geographic basis. This is a concept that modern theorists have returned to many times [27-31]. Further work highlighted the distinction between urbanisation and localisation economies and clustering, in particular the proximity between firms, shared infrastructure, better availability of specialised facilities and reduced risk and uncertainty for aspiring entrepreneurs [32]. Rosenfeld [33] (p.20) cites "tailored infrastructure" as a key advantage in regional development and propounds the use of a scale economy logic: "As industry concentration increases individual businesses benefit from the development of sophisticated institutional and physical infrastructure tailored to the needs of specific industry". This is important in that there needs to be a clear distinction between generalised urbanisation economies and true industrial clustering [34]. Industry clusters are also regarded as an important tool in policies related to national innovation systems, as enterprises do not conduct business in isolation, neither do they innovate in isolation [35]. The stimulus to innovate comes from a mix of competition, knowledge spill-overs and market pressure. "Innovation and the upgrading of productive capacity is seen as a dynamic social process that evolves most successfully in a network in which intensive interaction exists between those 'producing' and those 'purchasing and using' knowledge" [36].

\subsection{Clustering and SICS}

One of the standard approaches for discerning evidence of clustering activity is the use of location quotients. This process involves the researcher, on a bounded geographical basis, looking at the representation of firms with nominated SICs or logical groups of SICs and comparing their density with that of a peer group in the wider firm population, usually that covered by a country. Any group of firms or even industries with a location quotient greater than 1 indicates that there is a greater than average representation in the geographical area under study. This method therefore makes the assumption that such over-representation is a proxy for "activity", which is an indicator that the presence of such activity is generated by the presence of an active industrial cluster. An example of this is a UK wide study referred to as the Sainsbury Report [37]. The report was based on employment data and, although supported by qualitative information, it would not be expected, for example, to identify all embryonic or aspirational clusters. The reason for this is that the study to a large degree used Dun and Bradstreet (DNB) data (including employment), which itself uses SICs to identify types of firm activity. However, the DNB database is refreshed only every 2 years, and SICs can take much longer to capture firms based on new technologies. What might seem a simple firm count, however, has to take account of a host of factors, including the size of the firm, i.e. employment count, usually regarded as a robust measure of a firm's size. In the location quotients method linkages or associations between firms and activity such as non-traded interdependencies are discerned largely by inference. For example, if there is a strong electronics sector with a small average size of firms, with many new starts, then it would be expected that a noticeable venture capital sector should appear. The method also requires a fair assessment of the likely groupings that occur in practice. In other words, there is significant art on the part of the investigator when it comes to putting together appropriate 'groups' or 'templates' of aggregated firms [38, 39]. Feser 
and Bergman (ibid) commented: "We recognise that SIC codes do not capture the subtleties of industrial life and the complexities of cluster activity. The identification of these will be vital in further work to develop clusters."

\subsection{Problems with SICs}

Most cluster studies start with a database of firms and other organisations and try to discern patterns of common, or supportive, activity of trade, of knowledge exchange, of networks of co-operation, etc. By far the most popular starting point in putting together firm 'commonalities' is the use of SIC codes in order to establish the activity that an individual firm is engaged in. The two most common SIC systems in use in the UK have been the UK system [United Kingdom Standard Industrial Classification of Economic Activities (UKSIC)] and also those of the US, for example Dun and Bradstreet uses USSICS/NAICS. There are also a number of others, such as the EU supported NACE (Statistical Classification of Economic Activities) and the CPV (Common Procurement Vocabulary), although the latter tends to be used in the context of larger pan European Union (EU) purchasing contracts via the OJEU (Official Journal of the EU).

A Standard Industrial Classification (SIC) was first introduced into the United Kingdom in 1948 for use in classifying business establishments and other statistical units by the type of economic activity in which they are engaged. The classification provides a framework for the collection, tabulation, presentation and analysis of data and its use promotes uniformity. In addition, it can be used for administrative purposes and by non-government bodies as a convenient way of classifying industrial activities into a common structure. The system is now identical to the EUROSTAT System NACE at the four digit class level, and the United Nations system ISIC at the two digit Divisional level. Historically, the impetus for the introduction of these codes was to enable government agencies to better understand the make-up of industry when determining the national stock of businesses and their likely effect on the national economy.

All of these SIC classification systems have their shortcomings. The main ones are:

1) A level of detail that is too coarse to differentiate activities that are similar, but not the same. This was the case with the USSIC at the 4-digit level. This type of problem is addressed from time to time by the authorities expanding both the scope and the resolution of the numbering system with respect to the level of detail for industrial activities. This in itself can lead to the next problem below.

2) A level of detail that endeavours to cover every manufacturing and service activity known, but which may end up confusing the organisation asked to place itself in any particular category. Also, even quite small firms engage in more than one activity, yet most questionnaires used as the basis for eliciting SIC data allow for one primary and a small number of secondary classifications.

3) The use of more generalised categories such as 'Business Services'. In the event that it is not immediately obvious to the firm that a highly specific category exists for their particular firm's activities there is a temptation to place their organisation in this seemingly 'catch all' category. This is particularly true for service or knowledge based firms or those with a consultancy content across a wide range of services. With the rise of new types of 
firm activity, such as those associated with e-business, their development outstrips the capability of the authorities to keep pace with the emergence of such firms by the issuing of new SIC codes. Even with the best of intentions on the part of national authorities there is a natural time lag for an agreed new set of SICs to propagate through either the public or private industrial data collection systems. With classifications such as NACE there is the additional difficulty of getting all the EU member states to agree on changes for a common coding system, although, as noted above, the UK system has been compliant since 2003.

The above shortcomings are well-known by investigators and for some data sources a text descriptor of the firm's activities is often available. Again this is applied to the main line of activity rather than an attempt to capture a full understanding of the subtleties of diversified activities that so many modern firms are engaged in. This can be a particular problem with the ongoing trend towards flexible specialisation in manufacturing firms [40]. It is therefore such compromises that can undermine the accuracy of analyses, no matter how technically sophisticated the subsequent statistical processing. This difficulty was articulated by Porter [7] (p.204) when he complained, in relation to cluster boundaries, that: "they rarely conform to standard industry classification systems which fail to capture many important actors in competition as well as linkages across industries.... Because parts of a cluster often fall within different traditional industrial or service categories, significant clusters may be obscured or even go unrecognised". In a another example, Feldman et al [15] (p. 131,p. 139) note: "Innovative firms often defy classification by standard schemes as they create an industry segment by responding to market opportunities typically operating in niches not profitable for larger or established firms" and later they conclude "It is only through an appreciation of the nuances of cluster development that one might be able to inform policy adequately". There does not seem to be any single way to analyse clustering activity and indeed much depends on the desired scope of study on the part of the investigator. It would also seem that a combination of methods and data sources may yield the best understanding, but the downside is that such an approach requires time, resources and effort on a number of fronts and hence is expensive.

In the rest of this paper we propose a new method for determining a comprehensive picture of firm activity free from some of the constraints of an SIC-based system as outlined in this section.

\section{Methodology}

Big Data has emerged as a system of knowledge that is already changing the objects of knowledge and promises to bring new insights to our understanding of human networks and communities [41]. Big data analytics involves the ability to gain insight from data by applying statistics: mathematics when applied to data sets that demonstrate three important qualities, namely velocity, variety, and volume [11]. Velocity refers to the increasing speed with which data is created, variety to a wide range of unstructured data, while volume refers to the amount of data that can be collected and analysed. Web data sets supplemented by various other sources demonstrate all three qualities, with the size of the data set varying depending on the context of 
the study. These qualities carry an idealistic expectation about the potential to offer insights into a problem, which is well captured in the assertion by Boyd and Crawford [41] [p.663] that beyond technology and analysis, big data involves "mythology: the widespread belief that large data sets offer a higher form of intelligence and knowledge that can generate insights that were previously impossible, with the aura of truth, objectivity, and accuracy". Similarly, Graham and Shelton [42] argue that as "big data are increasingly embedded into social and spatial decisions, processes, and institutions, the links between signifier and signified might become ever more obfuscated". This may be first because the objects of signification are often inaccessible due to size, the proprietary-ness, or the black boxing of data sets, while even when data are available they can be refracted through aggregation, modeling, and filtering mechanisms. Big data and complementary techniques need to be applied, keeping the research objectives in focus and should not be applied for the sake of it or because data is available. Put differently, research should be driven by the big questions not the big data as such. Given the nature of our objectives, we underpinned our big-data approach work using a web mining technique which can be broadly defined as the discovery and analysis of useful information from the World Wide Web [43]. Web mining research overlaps substantially with other areas, including data mining, text mining, information retrieval, and Web retrieval and so on [44]. Such data collection and analytical techniques can be useful when it comes to addressing the shortcomings of the existing SIC-system approaches as outlined earlier. For example, an ad-hoc approach will not necessarily require maintaining a list of classification codes, given that these will emerge from the data. In turn this makes it possible to avoid the limitations resulting from classifications being out of date or narrow in scope to fit a wide range of activities (especially when it comes to novel ones). Similarly broad categories that act as a catch-all classification can become more granular and light can be shed on the black box of classification. Finally, given that an Internet-based system can shorten the data-collection, analysis and cluster identification cycle, it can become possible to shorten the cycle of new policy formulation when it comes to emerging economic clusters and activities.

Our proposed methodology has four main steps, revolving around data collection, processing, analysis and reporting. Although the details of these steps may vary depending on the research questions set, potential variations still share the underlying approaches. We outline how these steps work in the context of what we envisage as a typical scenario, i.e. a regional analysis.

\subsection{Selecting a test-case}

As in this paper our work has a methodological focus, the methodological steps to collect, analyse and present the result are of interest and not the interpretation of the results. Our testing was carried out with reference to a defined geographic basis, in this case an English region, namely the North East of England. The North East of England was selected as a test-case for our methodology for a number of reasons. Firstly, as developing a methodology would require much trial and error while optimising it, the size of the data sets involved should lend itself to such an iterative process. Equally importantly, from a regional innovation and policy perspective, the region historically has a wealth of innovative clusters that can provide an 
interesting backdrop. Both the region and the focus on policies have gone through a number of changes over the past 2 decades. As a cautionary note, as with many economic (and management science) constructs, the study of the various cluster concepts is subject to the vagaries of fashion in the sense that, at a particular point in time, many practitioners see the whole notion of industrial clusters as being a good route to economic development in their particular geographical area of interest or responsibility. As such, many regional economic strategies have been defined on the basis of industrial cluster theory until some other 'magic bullet' appears and the attention of policy makers moves on. The North East is no exception. The 2001 Regional Economic Strategy (RES) produced by the Regional Development Agency (RDA) had many references to a variety of cluster based strategies and initiatives. By 2005 responsibilities had changed within the RDA and the new RES published covering the same broad issues for the region contained no main references to industrial clusters at all. By 2013 smart specialisation and the economic development of EU regions avoiding duplication of efforts and making efficient use of scarce resources had become a top policy priority for fostering externalities and innovation in key enabling technologies across the EU $[45,46]$.

\subsection{Step 1: Big data collection}

A systematic analysis would typically involve accessing a firm's web site and then interrogating that site for key words that could be descriptors of activity. This is a simple enough task for individual sites and when done manually. However, it is not practical or feasible to look-up and interpret the information on thousands of web sites manually. Instead, an automated data collection system was developed. This was built with PHP (recursive backronym of PHP: Hypertext Preprocessor) and MySQL (Structured Query Language), using freely available libraries. PHP is a server-side scripting language designed for web development. PHP was considered an ideal case as it could both easily retrieve data from the web and store it in a relational database such as MySQL, but also because it could underpin the web-based presentation and of data later on.

The input for the data collection requires only the web site address to be retrieved and the geographic location of the company's registered address (e.g. using an address that could be translated to coordinates when needed). A web site address does not suffice to obtain a location by geo-tracking its Internet Protocol (IP) address, as company web servers do not reside at the same address as the company and may even be in a different country. For our test case we input data from a commercial database used primarily for market research purposes that also included SIC codes for each entry, making it possible to compare our results with the currently-used industry codes.

For our test case we retrieved the home page for each company (February 2016). It would have been possible to adopt a different sampling approach which would involve downloading multiple web pages instead of focusing entirely on a special one, such as the home page. " $A$ purely random selection procedure would be one where each page had an equal chance of being selected; but in practice this is not possible or necessarily desirable." [47] [p.97] Still, in our case, home pages were deemed to offer a sufficiently representative and consistent way of judging what the web site and in turn what the company is about. 
We only downloaded the web page code and not any images or other files associated with it, as we were interested in the text it contained and its meta-information (such as page title, description and keywords). The rationale for collecting the page content and meta-information was so that we could compare the effectiveness of these two approaches when it came to identifying and classifying a company's business activities. For each web site we stored a full copy of the page retrieved as a separate file. We also stored in the database a record of the address the page was retrieved from. Using a sequential process, we were able to parse about 1250 web sites/hour. This could be easily scaled up if bigger data sets are to be processed. After checking that a valid request was obtained, we processed each page to strip any code, effectively leaving just its main contents for analysis. The text obtained was stored in the database alongside the meta-information. Finally, we processed the web page text and the meta-information (combining the title, description and keywords into a single string) by applying MySQL stop-words and Porter's stemming. Stop words are common words that can be removed without affecting the meaning of a string (e.g. "an", "but", "you", "of", "still" etc.) in order to simplify the text stored and improve performance. The Porter stemming algorithm is a process for removing the most common morphological and inflexional endings from words in English, typically while undertaking a term normalisation process [48]. We used the PHP library provided by Porter to implement the stemming process. Table 1 below shows some examples of the Porter stemming process.

Table 1 Stemming examples

\begin{tabular}{|l|l|}
\hline Stemmed word & Original words \\
\hline technolog & technological technologies technology \\
\hline oper & operative operation operator operate \\
\hline electr & electrical electric electricity \\
\hline
\end{tabular}

Finally, we removed any single letter instances from the resulting texts. The processed text and meta-information were then used for our analysis. We started with an initial sample of 56,549 companies, out of which 13,526 had the address of their web site captured. For each of the companies we also noted their 2007 SIC code and postal address.

\subsection{Step 2: Data processing}

The processing steps will vary depending on the research questions with a view to increasing the quality and focus of the data set. "Large data sets from Internet sources are often unreliable, prone to outages and losses, and these errors and gaps are magnified when multiple data sets are used together" [41] [p.668]. Even though it may have been expected that home pages of company web sites would be well-maintained, offering a representative view of what the company does, this cannot be taken for granted. As such a number of steps may need to be taken in order to check and cleanse the data as much as possible. In this test-case, beyond stop-word removal and stemming, we conducted a number of processing actions on the dataset. Firstly, we checked again and removed all the companies whose meta-information contained bad requests. A bad request error typically involved an HTTP status code indicating that the request 
sent to the website server was distorted or incorrect and consequently the server could not understand it, or the page no longer existed. Typical bad requests consist of keywords like "bad request", "object moved" and "page exist" (this was "page not exist" before stop word removal). Considering bad requests may add interferential noise for clustering, we removed these companies to achieve more representative clustering results. Secondly, we removed all the companies whose meta-information was empty. Missing values made no contribution to text mining tasks, especially when it came to consistently comparing different approaches to text entering the analysis. They also add unnecessary computational overheads. Similarly, we removed all the companies whose meta-information and home page contained fewer than 50 words, as we typically found them not to contain adequate relevant company information. Thirdly, companies without SIC codes in our input data sets were removed, as it would not be possible to undertake a comparison with the cluster generated by our methodology. Finally, terms which occurred in fewer than 5 instances were removed [49]. These special words are not informative in clustering tasks. This is similar to how words that occur very frequently were removed. For instance words such as "world", "work", "uk", "support", "service" "search" etc., do not contain information about which industries companies belong to. Petterson and Hurdle [50] used 0.1 as a threshold, that is, they considered words occurring in more than $10 \%$ of a document as corpus specific stop words. We chose the more conservative value of 0.2 , which resulted in terms like "studi", "train", "legal" being included in the data set used for the analysis. During this final step, we also removed all entries that end up with zero or one word. The above processing steps were performed before we conducted any specific comparative tests. After processing the data, the final dataset contained 8,578 entries. 4,948 companies were rejected since their webpage content did not meet our criteria.

\subsection{Step 3: Data analysis}

The data analysis used the processed text and meta-information to identify the business activities of each company and then clustered them into "topics". A topic is a collection of terms describing what the activity is. In this study, "topics" for documents corresponds to "industrial clusters" for companies. This is similar to how SIC codes describe the primary activities of a company. For the data analysis we used three methods in order to compare their efficiency and effectiveness.

The first method was the Latent Dirichlet Allocation (LDA). Latent Dirichlet Allocation is an unsupervised graphical model that can automatically discover latent topics in unlabelled data. This approach has been thoroughly explained in the paper by Blei et al. [51], and also in Griffiths and Steyvers [49]. Through applying LDA, each document is modelled as a mixture of $K$ latent topics, where each topic, $k$, is a multinomial distribution $\varphi k$ over a $V$-word vocabulary. Given an input corpus $W$, the LDA learning process consists of calculating $\Phi$, a maximum-likelihood estimate of model parameters. Given this model, we could infer topic distributions for arbitrary documents. For practical consideration, the topic with highest probability could be assigned to a document accordingly.

The second analytical method was hierarchical clustering. Hierarchical clustering is a classic algorithm for document clustering. It is widely adopted in document clustering tasks. Zhao et al. 
[52] have found that hierarchical clustering showed good performance in providing a view of the data at different levels of granularity. According to Rokach and Maimon [53], hierarchical clustering is subdivided into agglomerative methods, which proceed by a series of fusions of the $n$ objects into groups, and divisive methods, which separate $n$ objects successively into finer groupings. In this study, we choose to use the agglomerative method as it has been commonly used in previous literature [54]. In this method, each entry starts in its own cluster, and pairs of clusters are merged as one moves up the hierarchy. At each particular stage the method joins together the two clusters that are the closest. This iteration continues until the number of clusters reaches the designated size.

The final analytical method is K-Means Clustering with tf-idf weights. K-means is also a commonly used algorithm designed to find coherent groups of data. For numerical clustering, $\mathrm{K}$-means can perform well since the distance between every two numbers can be measured directly. For high-dimensional data such as text documents, K-means has also been proved to be appropriate for clustering tasks [55-57] and the result generated by K-means was closed to manual clustering. We followed the practice of Zhong [58] and Balabantaray et al. [59] to make a bag-of-words assumption and generated a document-term matrix for the entire corpus. Due to the different size of the document, we also applied tf-idf to normalise the values in the matrix. Each document could then be represented by a vector of tf-idf scores. The tf-idf, or term frequency-inverse document frequency, was a weighting scheme which reflected how important a word was to a document in a corpus. For terms that appeared many times in the corpus, but were only contained in a small subset of the documents, a high tf-idf score was assigned.

\subsection{Step 4: Presenting the data}

The presentation of the results depends on the research questions or application of the proposed methodology. For instance, there may be cases where listing of the cluster and the associated terms may suffice. In other cases the information could be superimposed on maps to make it visually easier to understand. For example, the companies in a cluster can be placed on a map and heat maps generated in order to visually identify areas of intense activity for a specific cluster. Such tools can be complemented by forms that contain search criteria that adjust to the data. Different combinations of search criteria could generate different result sets to visualise, if near real-time analysis is possible. This will mostly depend on the number of companies in a data set and the size of the generated corpus. The results could then be interpreted in a number of ways for the clusters and industries to be identified. In our test case we will be presenting below two such approaches to labelling clusters.

\section{Results}

\subsection{Comparison of analyses}

Given the exploratory nature of our work, we test the effectiveness of the algorithms by undertaking a comparison of the findings vs. the 2007 SIC primary SIC codes. According to the UK Kingdom Standard Industrial Classification of Economic Activities instruction, the SIC code 
system contains 21 big sections from section A to section $U$. Under these 21 sections there are 88 sub-topics. Consequently, in order to undertake a consistent comparison of the three clustering approaches, the number of topics was fixed at 21 and 88 for two comparative tests respectively. We employed three methods to test the relevance between our results and SIC code classification. The first method was Chi-square test for independence with the significance level set to 0.05 . The Chi-square test is applied for two categorical variables from a single population. It is used to determine whether there is a significant association between the two variables. The second method was an entropy-based test. This tests the relevance of two samples using a likelihood ratio. A smaller entropy indicates more significant relevance between the two variables tested. The final method was the F-measure, a classical test for the performance of classification. F-scores, defined as the weighted harmonic mean of the precision and recall of the test, can be used as a single measure of classification accuracy. The value of F-score ranges from 0 to 1 , with a larger F-score indicating more significant relevance. The results of the comparison are summarised in Table 2.

Table 2: Comparative test for three proposed analytical approaches

\begin{tabular}{|l|r|c|c|c|}
\hline Method & Time (s) & P-value of Chi-Square & Entropy & F-score \\
\hline 21 topics & & & & \\
\hline LDA & 622 & 0 & 1.9423 & 0.3702 \\
\hline H-Cluster & 25160 & Not satisfactory & 2.5872 & 0.1143 \\
\hline K-means & 5372 & Not satisfactory & 2.2421 & 0.2899 \\
\hline 88 topics & & & & \\
\hline LDA & 647 & 0 & 2.2321 & 0.2890 \\
\hline H-Cluster & 26330 & Not satisfactory & 3.2980 & 0.1130 \\
\hline K-mean & 19788 & Not satisfactory & 3.0762 & 0.2391 \\
\hline
\end{tabular}

For the Chi-square test for independence, conditions were not satisfied for the $\mathrm{H}$-cluster and the K-means algorithms since the data size is not large enough. Results clustered by LDA showed P-value of zero for both 21 topics and 88 topics, indicating that this cluster significantly relates to SIC code classification. Entropy also showed a consistent result with the chi-square test. The LDA method generated the smallest entropies (1.9423 for 21 topics and 2.2321 for 88 topics), achieving the best performance among the three approaches. Similarly, when it came to the F-measures, the score of LDA was 0.3702 for 21 topics, which is much larger than the score of hierarchical clustering (0.1143) and K-means clustering (0.2899), suggesting that the LDA had the most significant relevance to the SIC code classification. This was also the case when we undertook the test using 88 topics. As LDA generated the most relevant result when compared to current SIC code classification and at a fraction of the time needed by the other approaches we adopted this method for all our further tests.

\subsection{Comparing different text-sets}

In this step we examined the potential difference that using different parts of a web page could make to the analysis and results. More specifically, we tried LDA using three different text sets [20]. The first one contained the web page text that is typically visible to users when visiting a web site. In the second we only used the meta-information typically used for indexing pages by 
search engines, such as a description of what the page contains (we are only considering home pages), keywords, the author of the document, last modified, other metadata etc. One would expect business to include in the meta-fields (especially in the description and keywords) those terms that are the most relevant to what the company undertakes. On the other hand, meta-fields may be used as part of search engine optimisation efforts and consequently more creative approaches to setting them may be used. Finally, we combined the web site and meta-fields into a single data set (Total). We repeated the tests of the previous step for each of them and summarised the results in Table 2. All three tests generated consistent result showing that "Total" feature performed better than "Web content" and "Meta information". The only disadvantage of employing "Total" is the longer time of clustering, but 523 seconds is an acceptable number. For the analysis we used a machine that had $4 \mathrm{CPU}$ cores clocked at $4.0 \mathrm{GHz}$ and $16 \mathrm{~GB}$ memory. For the analysis a single core was used while utilising the gensim package (in a development environment based on Python 2.7.9 / Windows 10). Based on this evidence we decided to use the combined data set for the next step.

Table 3: Comparison of three different text-sets

\begin{tabular}{|l|c|c|c|c|}
\hline & Time (s) & P-value of Chi-Square & Entropy & F-score \\
\hline Web content & 412 & 0 & 1.9212 & 0.3008 \\
\hline Meta information & 88 & 0 & 2.322 & 0.2877 \\
\hline Total & 523 & 0 & 1.8772 & 0.3421 \\
\hline
\end{tabular}

\subsection{Choosing the number of topics}

So far we have been benchmarking our methodology against the SIC code, fixing the number of clusters to what the SIC code proposes. The next question arising was whether this was an appropriate number of clusters to have. We lifted this restriction and attempted to use log-likelihood, to find the optimal number of topics for our dataset. Log likelihood is a measure of model fit in topic modelling to see how well a probability distribution or probability model predicts the entries in a test set. Generally speaking, higher log probability of a model indicates better performance. We tested a series of numbers to find the optimal number of topics to achieve the lowest perplexity. Figure 1 shows the number of topics along with the log likelihood. The bars show $95 \%$ confidence interval of the log likelihood, estimated by 10 iterations. When the number of topics was around 36, the log likelihood reached the highest point in these trials. When the number of topics was between 20 and 42, the log likelihood remained relatively stable, with fluctuation likely to be due to noise. After 42, the log likelihood showed a clear downward trend. So, moving forward for the remaining tests, we fixed the number of topics at 36.

Figure 1: Choosing the optimal number of topics 


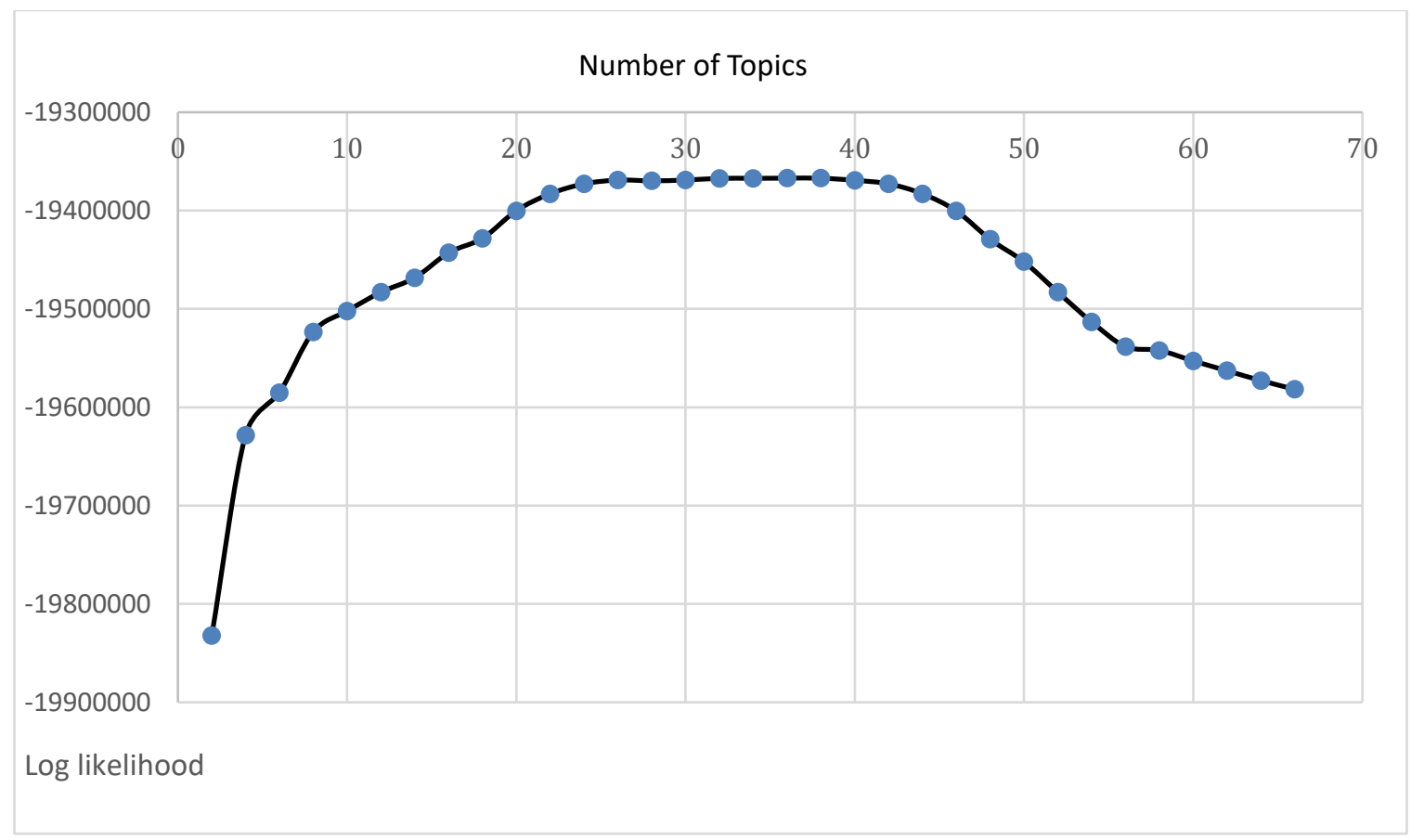




\subsection{Labelling the topics}

We considered two approaches for labelling the latent topics. The first approach follows the method used by Blei et al. [51]. In their research, the label of each topic can be illustrated via the top most frequent words (words that have high probability under that topic) in each topic [49, 51], or alternatively by manual labelling of each topic based on domain knowledge and subjective interpretation of each topic [60].

In this study, in order to improve the performance of clusters, we progressively removed "common" words from the result manually, in order to improve the final results. When getting the initial clusters of LDA, we inspected the top five words under each topic. Once we identified a word that was not contributing to topic interpretation, we removed that word from the raw dataset. After this activity and having gone through all the topics, we reran LDA to obtain a revised set of results. We list below a few examples of such terms. For example, given that we knew the address of each company we were able to remove any references of the address from the company's web site data.

Table 4a: criteria for word removal (without removing words) [51]

\begin{tabular}{|l|l|}
\hline Word Type & Examples \\
\hline address & Northumberland, newcastl, ashington \\
\hline orientation & north, eastern, southeastern \\
\hline month & April, June, July \\
\hline web term & login, skip, main \\
\hline equivocal words & bai, cgi, tyn \\
\hline human name & Ben, Peterson, esmond \\
\hline
\end{tabular}

Such an iterative process can be repeated several times until satisfactory results are obtained. For this study, the iteration was repeated six times. Below we present two tables, showing the input (Table $4 \mathrm{~b}$ ) and output (Table $4 \mathrm{c}$ ) results of this process. As can be observed, in Table $4 \mathrm{~b}$ a few top words are not contributing significant information to the topic. For example, "sunderland" in topic 3 and "jan" in topic 21. 
Table 4b: Top 5 words of topics following Blei (without removing words) [51]

\begin{tabular}{|c|c|c|c|c|c|c|}
\hline$\#$ & Amount & & & Terms & & \\
\hline 1 & 108 & clean & wishlist & prescript & add & caravan \\
\hline 2 & 328 & school & fire & safeti & wast & nurseri \\
\hline 3 & 264 & domain & host & golf & onlin & order \\
\hline 4 & 663 & event & book & club & wed & sunderland \\
\hline 5 & 147 & properti & rent & report & let & landlord \\
\hline 6 & 55 & bike & damp & cycl & road & optima \\
\hline 7 & 153 & hire & equip & lift & plant & tool \\
\hline 8 & 328 & properti & sunderland & counti & peterle & commerci \\
\hline 9 & 201 & add & shop & inch & accessori & cart \\
\hline 10 & 356 & door & window & roof & sunderland & instal \\
\hline 11 & 57 & fenc & stock & samsung & hospic & timber \\
\hline 12 & 149 & car & asbesto & sport & centr & rover \\
\hline 13 & 106 & cooki & mail & deliveri & onlin & royal \\
\hline 14 & 312 & care & treatment & recruit & viagra & health \\
\hline 15 & 281 & manufactur & suppli & contract & cater & construct \\
\hline 16 & 165 & film & hellip & music & studio & student \\
\hline 17 & 556 & engin & consult & technolog & innov & data \\
\hline 18 & 413 & energi & heat & account & instal & plan \\
\hline 19 & 80 & food & turf & vat & pave & synthet \\
\hline 20 & 99 & kitchen & taxi & dental & bedroom & sunderland \\
\hline 21 & 208 & event & safeti & commun & peopl & educ \\
\hline 22 & 70 & bui & index & mortgag & architectur & jan \\
\hline 23 & 487 & insur & secur & advic & start & cost \\
\hline 24 & 837 & learn & cours & health & peopl & consult \\
\hline 25 & 120 & floor & bathroom & tile & wood & carpet \\
\hline 26 & 310 & softwar & web & funer & comput & digit \\
\hline 27 & 288 & repair & vehicl & car & ndash & tyre \\
\hline 28 & 74 & storag & babi & pan & chicken & kebab \\
\hline 29 & 99 & glass & furnitur & landscap & john & art \\
\hline 30 & 257 & bull & fabric & print & steel & engin \\
\hline 31 & 122 & hair & sign & salon & beauti & shop \\
\hline 32 & 71 & garden & park & farm & curtain & blind \\
\hline 33 & 63 & web & cod & seo & interior & onlin \\
\hline 34 & 116 & rsaquo & electr & test & marin & group \\
\hline 35 & 564 & control & light & pump & manufactur & suppli \\
\hline 36 & 71 & flower & packag & pack & box & cake \\
\hline
\end{tabular}


Table $4 \mathrm{c}$ below shows the top 10 terms for each cluster after the iterative removals. We have also manually added a column interpreting the cluster activities as captured by the top terms.

Table 4c: Top words after 6 iterations

\begin{tabular}{|c|c|c|c|}
\hline \# & Amount & Cluster & Top 10 terms \\
\hline 1 & 419 & $\begin{array}{l}\text { computer and data } \\
\text { processing services }\end{array}$ & $\begin{array}{l}\text { domain softwar host web storag comput control air oper } \\
\text { server }\end{array}$ \\
\hline 2 & 237 & leisure goods and gifts & $\begin{array}{l}\text { tea golf hair caravan landscape flower wed park special } \\
\text { shop }\end{array}$ \\
\hline 3 & 957 & airline services & $\begin{array}{l}\text { consult web innov technolog skill cost organis brand } \\
\text { agenc studi }\end{array}$ \\
\hline 4 & 45 & hotels and travel & $\begin{array}{l}\text { holidai cheap amp cruis roll cottag travel entertain villa } \\
\text { mussel }\end{array}$ \\
\hline 5 & 57 & fast food restaurant & kebab architect chip pest song pizza garlic chicken die und \\
\hline 6 & 363 & Engineering equipment & $\begin{array}{l}\text { equip control water manufactur technolog valv unit tube } \\
\text { power applic }\end{array}$ \\
\hline 7 & 253 & $\begin{array}{l}\text { sales and repair of motor } \\
\text { vehicles }\end{array}$ & repair tool equip machin vehicl tyre car brake mot garag \\
\hline 8 & 92 & testing and certification & $\begin{array}{l}\text { chemical sign plastic laboratori tank set loft standard } \\
\text { convers smoke }\end{array}$ \\
\hline 9 & 256 & estate agent & $\begin{array}{l}\text { properti let floor bedroom agent rent estat landlord } \\
\text { residenti commerci }\end{array}$ \\
\hline 10 & 68 & $\begin{array}{l}\text { energy and power } \\
\text { generation }\end{array}$ & $\begin{array}{l}\text { energy power oil check renew certif measur cotton solar } \\
\text { recycle }\end{array}$ \\
\hline 11 & 148 & $\begin{array}{l}\text { plumbing, heating and } \\
\text { air-conditioning }\end{array}$ & $\begin{array}{l}\text { heat instal bathroom boiler plumb water fenc repair } \\
\text { shower tree }\end{array}$ \\
\hline 12 & 277 & educational institution & $\begin{array}{l}\text { school commun acdem parent educ children learn } \\
\text { academi drive child }\end{array}$ \\
\hline 13 & 690 & event management & event book centr entertain open famili hall food visit castl \\
\hline 14 & 247 & pet supplies \& care & treatment care pet health clinic dog fit weight turf beauti \\
\hline 15 & 191 & $\begin{array}{l}\text { management consulting } \\
\text { services }\end{array}$ & $\begin{array}{l}\text { financi plan advic mortgag invest independ advis pension } \\
\text { protect insur }\end{array}$ \\
\hline 16 & 34 & survey services & $\begin{array}{l}\text { secur index monitor safeti iso system screen mortgag } \\
\text { survei }\end{array}$ \\
\hline 17 & 115 & mail and post services & cooki mail deliveri onlin royal intern item send track user \\
\hline 18 & 166 & sports club & $\begin{array}{l}\text { fun club academi footbal ticket event member student } \\
\text { leagu colleg }\end{array}$ \\
\hline 19 & 514 & care activities & $\begin{array}{l}\text { care peopl learn health commun funer person plan famili } \\
\text { staff }\end{array}$ \\
\hline 20 & 194 & $\begin{array}{l}\text { law and legal consultancy } \\
\text { activities }\end{array}$ & $\begin{array}{l}\text { report result sustain legal law consult strategi video } \\
\text { corpor media }\end{array}$ \\
\hline 21 & 396 & $\begin{array}{l}\text { property maintenance, } \\
\text { development, decoration }\end{array}$ & $\begin{array}{l}\text { door window kitchen fit decor instal galleri floor } \\
\text { conservatori joineri }\end{array}$ \\
\hline 22 & 123 & security & $\begin{array}{l}\text { secur protect packag printer interior cctv guard alarm } \\
\text { suppli document }\end{array}$ \\
\hline 23 & 540 & $\begin{array}{l}\text { manufacturing and } \\
\text { engineering }\end{array}$ & $\begin{array}{l}\text { engin manufactur fabric steel machin suppli marin metal } \\
\text { group facil }\end{array}$ \\
\hline 24 & 473 & building construction & $\begin{array}{l}\text { clean commerci mainten construct contractor domest } \\
\text { complet landscap contract builder }\end{array}$ \\
\hline
\end{tabular}




\begin{tabular}{|c|c|c|c|}
\hline 25 & 118 & accessories \& clothing & roof women cloth dress babi men shoe jacket boot top \\
\hline 26 & 78 & taxi transportation & $\begin{array}{l}\text { taxi race fee driver northern airport travel citi night } \\
\text { motorcycl }\end{array}$ \\
\hline 27 & 173 & $\begin{array}{l}\text { electrical installation and } \\
\text { maintenance }\end{array}$ & electr light instal taxi cabl led kit test cast lamp \\
\hline 28 & 127 & energy saving activities & $\begin{array}{l}\text { environ pump solar green pill save panel wood damp } \\
\text { renew }\end{array}$ \\
\hline 29 & 123 & $\begin{array}{l}\text { medical support and } \\
\text { services }\end{array}$ & $\begin{array}{l}\text { hospital safeti insur health support aid plant medic track } \\
\text { equip }\end{array}$ \\
\hline 30 & 201 & $\begin{array}{l}\text { vehicle dealers and } \\
\text { support }\end{array}$ & car vehicl van drive motor part dealer nissan travel model \\
\hline 31 & 280 & $\begin{array}{l}\text { accounting, auditing \& } \\
\text { book keeping }\end{array}$ & $\begin{array}{l}\text { account tax social financ start charter vat payrol corpor } \\
\text { sage }\end{array}$ \\
\hline 32 & 80 & personnel recruitment & $\begin{array}{l}\text { recruit job engin candid vacanc temporari blast storag } \\
\text { personnel employ }\end{array}$ \\
\hline 33 & 68 & interior design & $\begin{array}{l}\text { glass prescript dental frame smile test lens cosmet dentist } \\
\text { sunglass }\end{array}$ \\
\hline 34 & 190 & $\begin{array}{l}\text { manufacture of glass } \\
\text { products }\end{array}$ & add shop inch cart bed wishlist accessori gift item onlin \\
\hline 35 & 167 & $\begin{array}{l}\text { photography, graphic } \\
\text { design and video editing }\end{array}$ & $\begin{array}{l}\text { print card film digit barcod studio photographi dvd } \\
\text { graphic video }\end{array}$ \\
\hline 36 & 118 & environment protection & $\begin{array}{l}\text { wast asbesto recycl claim ship survei remov environment } \\
\text { treatment port }\end{array}$ \\
\hline
\end{tabular}

To put the effectiveness of this approach into perspective we compared it to a second approach. The second approach for selecting labels used a score for word set mutual information (MI) between the given topic and the word. According to the definition of Tirunillai and Tellis [61], given the presence of the word in a designated topic, MI could measure the amount of "information" gained by the topic. In other words, if a word has high MI, it may contribute more significantly to that topic. For measuring MI, Tirunillar and Tellis [61] suggest using entropy to measure the probability that a topic generates a randomly chosen document. In other words, topics with high entropy are evenly distributed across many documents while topics with low entropy are concentrated in fewer documents. Below is a formula for calculating the entropy of topic $k . \eta$ here represents the condition that the document involves the $k$ th topic.

$$
E(k)=-\sum_{\ell=0}^{1} P(\eta=\ell) \log _{2} P(\eta=\ell)
$$

If we condition the above distribution on a particular word type $w$ by normalising the number of $w$ appearing in each document (in topic $k$ ), the entropy formula could be modelled conditionally on that word as:

$$
E(k \mid W)=-\sum_{w=0}^{1} P(W=w) \sum_{\ell=0}^{1} P(\eta=\ell \mid W=w) \log _{2} P(\eta=\ell \mid W=w)
$$

The difference between the above two terms expresses the MI gained for topic $k$ as a result of 
the presence of word $W$. The formula is shown below:

$$
M I(k \mid W)=E(k)-E(k \mid W) \geq \forall(k, W)
$$

The $\mathrm{MI}$ is zero if word $W$ could not provide any information about topic $k$. If, on the other hand, W occurs many times in only a few documents about topic $k$, MI will be high. We consider that words with higher $\mathrm{MI}$ in each topic may be considered as a label of a corresponding topic. Table 5 shows the terms which were ranked high by MI for each topic. Comparing the results of Tables $4 \mathrm{c}$ and 5 we concluded that those in Table $4 \mathrm{c}$ were more effective. Top words could better convey the industrial attribute of each topic. For instance, topic 31 in Table 4c clearly represents the accounting services industry, but we could hardly interpret the industrial attributes of topics from MI methodology.

Table 5: Words of highest MI of topics

\begin{tabular}{|c|c|c|c|c|c|}
\hline \multirow{2}{*}{$\begin{array}{l}\# \\
1 \\
\end{array}$} & \multicolumn{5}{|c|}{ Terms } \\
\hline & local & Live & health & confid & donat \\
\hline 2 & domain & accord & store & browser & bui \\
\hline 3 & pop & andrea & girl & factori & advisor \\
\hline 4 & manufactur & Oper & kei & detect & suppli \\
\hline 5 & citroen & Bmw & tyre & model & test \\
\hline 6 & smile & dentist & $\tan$ & wholesal & brand \\
\hline 7 & power & technic & technolog & pump & oil \\
\hline 8 & pipe & precis & metal & compon & weld \\
\hline 9 & yell & Rep & grass & mind & wife \\
\hline 10 & januari & Form & club & merger & jason \\
\hline 11 & enquiri & Heist & candl & solicitor & rose \\
\hline 12 & econom & Rail & henri & peer & grove \\
\hline 13 & track & Fear & bath & suppli & weather \\
\hline 14 & harder & Pave & gambl & punch & emot \\
\hline 15 & movement & competitor & mari & short & cost \\
\hline 16 & innov & Lsquo & core & left & prestigi \\
\hline 17 & primari & Child & member & prior & shoe \\
\hline 18 & affect & Reel & size & luxuri & fitter \\
\hline 19 & count & permit & twitter & demand & big \\
\hline 20 & critic & Agre & monei & spot & technician \\
\hline 21 & network & exampl & trial & affair & futur \\
\hline 22 & morn & address & reduc & flow & metr \\
\hline 23 & german & prevent & flower & board & jan \\
\hline 24 & control & Rent & cancer & emailprotect & newham \\
\hline 25 & issu & languag & finest & foreign & venu \\
\hline 26 & unit & Hub & basket & fan & creativ \\
\hline 27 & undertak & Boi & mason & download & mobil \\
\hline 28 & editor & offshor & actor & helena & address \\
\hline
\end{tabular}




\begin{tabular}{|c|c|c|c|c|c|}
\hline 29 & materi & instant & inject & aggreg & chariti \\
\hline 30 & interior & Fair & altern & environ & technic \\
\hline 31 & internation & Emea & chill & wool & lone \\
\hline 32 & authoris & section & sheet & greatest & mdash \\
\hline 33 & therapi & Farm & patient & bai & fit \\
\hline 34 & york & rental & sail & accommod & locat \\
\hline 35 & letter & Good & parcel & print & visit \\
\hline 36 & manchest & steelwork & south & staircas & forg \\
\hline
\end{tabular}

\subsection{Further study on the "Other" categories in the SIC code system}

The UK SIC code has "other" categories whose SIC codes end in "09" or "90". For example, the category "Manufacture of other non-metallic mineral products" has a sub-category named "Manufacture of other ceramic products", which has an SIC code of 23490. The category "Wholesale of household goods" also has a sub-category named "Wholesale of other household goods", whose category's SIC code is 46490 . Reviewing the whole SIC code system, we observed that there is at least one "other" tag below each industrial classification. Given the names of these "other" categories, it is hard for users to interpret what these industries really do. We implemented LDA on these "other" categories to sub-divide them into more specific classifications. Also, top words of these classifications can be used as a label to indicate their detailed business. We chose the largest "other" category as a sample to assess the performance of LDA. "Management consultancy activities other than financial management" is the largest "other" category in the SIC code system (code: 70229). This category contained 156 samples. From the SIC code name, we can only deduce that this industry provides management consultancy services. However, after the further classification of LDA, this category could be summarised as follows:

Table 6: detailed classification of category 70229

\begin{tabular}{|c|c|c|}
\hline Category 1 & Category 2 & Category 3 \\
\hline consult & consult & strateg \\
\hline skill & invest & improv \\
\hline peopl & asset & web \\
\hline chang & account & advertise \\
\hline advic & fund & host \\
\hline learn & sector & consult \\
\hline improv & perform & impact \\
\hline train & plan & host \\
\hline sector & advic & create \\
\hline profession & event & local \\
\hline
\end{tabular}

Table 6 provides detailed information about the "Management consultancy activities other than financial management" category. For example, companies of category 1 provide management-training services. Companies of category 2 provide consultancy services relating to 
investment, property and assets, while companies of category 3 focus on advertising, providing customers with services about product and brand promotion. The terms in each column are the top-words under each topic, using the top words approach. The results are rather similar, which may be accounted for by the relatively small size of the clusters considered, compared to those presented in Tables $4 \mathrm{~b}$ and 4c. This analysis demonstrates the potential of our algorithm to provide more detailed insights when it comes to cluster classifications compared to the existing SIC-code system.

\subsection{Visualising clusters}

Big data analysis is often carried out relatively informally, generating vast amounts of "isolated" information, which managers might spend significant time making sense of [62]. Helping managers make sense of the results is therefore as important as the implementation of the analytics approach itself. In our case, depending on the application for which the cluster information was generated, it may be useful to complement the terms generated with a visual representation. Given that for each record its geographic address was known, it was possible to superimpose web sites and clusters on maps. The visualisations below were created with the Google Fusion Table service, which makes it possible to process large data sets. We plotted two different clusters, one using markers to show the positions of companies in the cluster (with a North East main address) and one using a heat map to represent the distribution. Heat maps were created for visualisation convenience in order to highlight any underlying effect. All points were weighted equally, with the same output parameters used.

\section{Visualising the "management and consulting services" cluster [ $n=191]$}
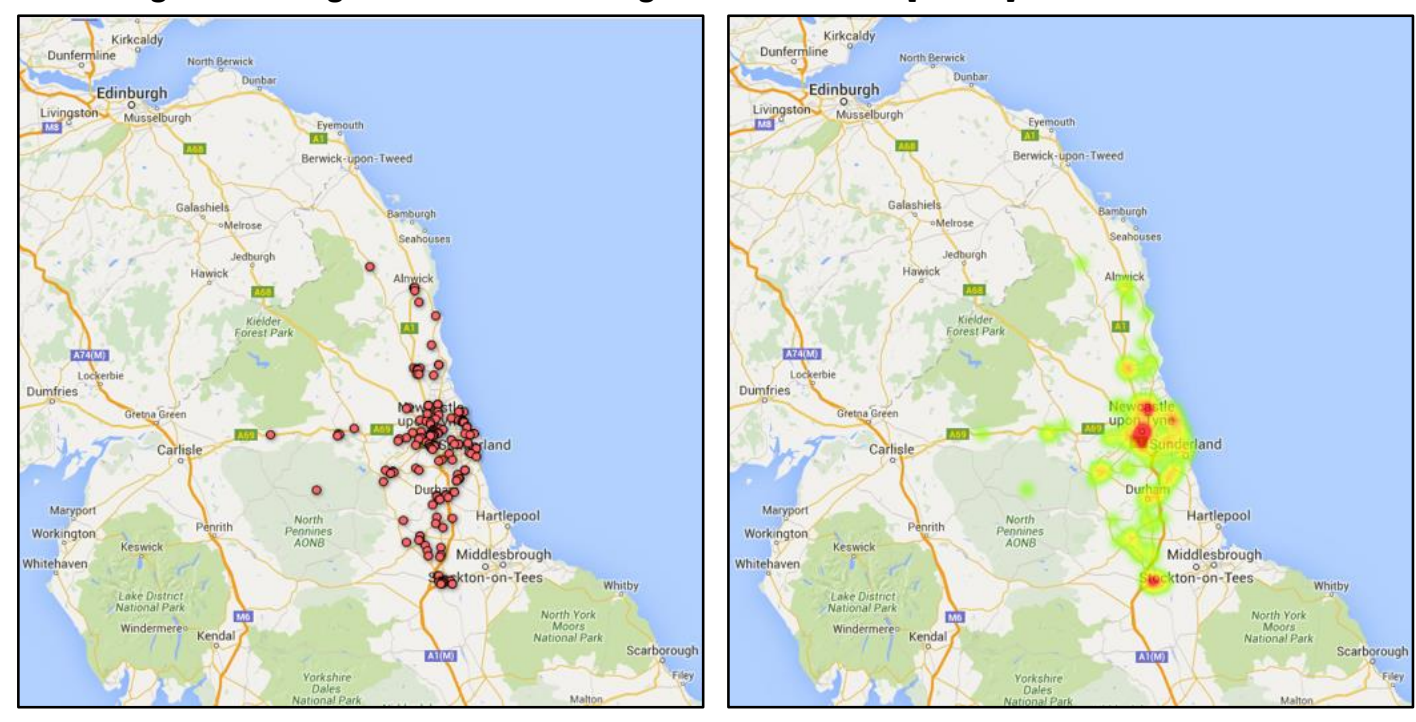
Visualising the "accessories \& clothing" cluster [n=118]

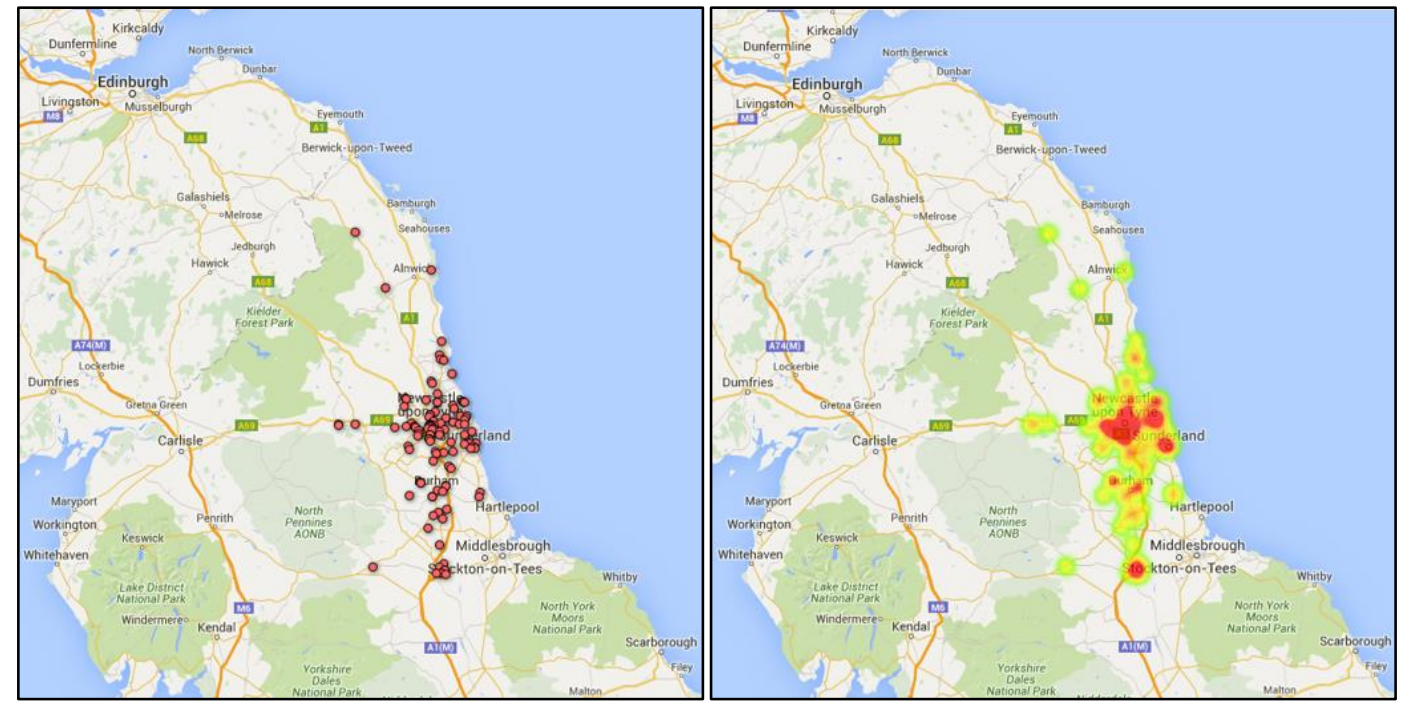

\section{Conclusion}

The cluster concept has captured the imagination of policymakers and the attention of scholars and business strategists in the last few decades. Clustering behaviour is such a pervasive aspect of modern economies and global trade that it draws the attention of many different disciplines and benefits from their scholarship. In this paper we have proposed a big data analytics methodology by which the Internet can help to elicit 'real time' data and knowledge about the firm in a cluster context, together with its interactions with other firms within a defined regional setting. Given the evolving nature of the web, the contribution to knowledge from the research is a combination of what can be done now together with an informed prediction of what may be possible in the future for supply chain management beyond individual single supply chains. In this sense our research also provides pointers to the limitations associated with such a big data approach to using the Internet as a meaningful repository of knowledge related to firms, and their industrial activities as they are reflected through their web presence over time.

The proposed approach to using the Internet as an additional source of data to automatically provide cluster analysis of companies can help alleviate a few limitations of using SIC codes and in doing so make a number of important contributions. First, SIC code needs a much longer time frame to update. Using Internet as a data source and through big data analytics there is great potential to provide a more dynamic and up to date stream of data and knowledge about supply chains within a regional setting. Second, there are difficulties even for company owners/key employees identifying which SIC category to choose. An automatic approach can help address this issue. Third, in the analysis of the "Others" category of SIC codes, we can see that our methodology can provide a more fine grained analysis given a big category. This echoes the need for greater granularity in cluster analysis, which is very difficult with existing data sources such as SIC codes. With the possibility of visualising a large number of firms' activities for business strategists and policy makers alike, it can provide a more intuitive 
understanding of the status quo and emerging trends. When given data sets from different time periods for the same geographical region, the mapping of evolutionary development of those business clusters can provide deep insights that no-one would be able to detect without such an approach.

When it comes to the practical implications, knowledge about geographical cluster distributions is critical for supply chain and operational decisions. For example, cluster analysis can inform better supply chain integration decisions, and the overall performance of a supply chain [63]. Geographical information about companies could be of particular importance for some supply chains such as the food industry [64]. Our proposed methodology can potentially underpin decision support systems that aim to inform policy and practice in terms of shifting policies for strategic co-operation from "accidental brokerage" to "purposeful brokerage" [65] and supply chain management, both with single or multiple supply chains. Supporting decision making is a complex task and many new systems will probably need to be built to exploit new data streams. Decisions can vary from policy ones, which are complex, non-routine, to day-to-day simple routines ones [66]. Typically, current applications for the new data sources and analytics are focused on tactical, operational control and operating decisions [67], falling into the operational level as opposed to the strategic one. Using a bespoke search engine it is possible to crawl the web sites of firms or other organisations on a large scale for a defined geographical area. It is then possible to run a series of queries to explore or probe in detail the structure of firm activity in a defined area, instead of just relying on the SIC information alone. The notion of combining, say, a database of a corpus of industrial firms within a defined geographical boundary with relevant information gleaned from individual company websites is very promising for mapping through big data analytics company activities. It holds out the prospect of gaining descriptive knowledge about company activities not captured by current SIC descriptors. In doing this we are aiming to offer a potential avenue for investigation when it comes to dealing with dynamic environments using business analytics [68]. In turn, early identification of the emergence of clusters can enable policy makers to support these clusters proactively, facilitating their development and boosting their chances of success through "purposeful brokerage" and the optimisation of supply chains within and across regional settings. Policy interventions and cluster management for allocating scarce resources stand to benefit from an Internet driven "early warning system" so that all relevant government agencies or other actors, such as cluster management teams or strategic initiatives for partnerships, can identify and profile new industrial emerging 'high velocity' clusters accurately and/or improve pre-existing SICs in a timely manner. Also, a wider pool of information sources (e.g. from company collaborations as captured by links on web sites, news information about collaborations, social media accounts or even internal data) can be used to extend the mapping and offer more granular insights into the interactions among clusters and the companies they consist of. Such an approach can make it possible to focus on specific dimensions, attributes or points of interest, for instance sustainability [69] and explore how trends develop over time.

\section{Future research}

Future research could apply our big data methodology to other regions and compare and 
contrast the results against different contextual settings and supply chains. This will provide tangible evidence of the methodology's ecological validity. In particular, it would be interesting to test the methodology in different geographic units, for instance, a metropolitan city or even an entire country. It may also be useful to compare data sets longitudinally, making it possible to study the formation and dissolution of clusters over time. When it comes to the methodology itself, in addition to descriptive information about a business, it may be possible to include other useful information that could also be sourced from the Internet. Operations and supply chain managers can embrace a model-based decision making paradigm while realising that useful models based on big data will quite often require a potentially significant commitment [70]. In cluster research the whole notion of the vitality of a working cluster relies on communication of some sort between constituent members, which implies a network architecture of collaboration and/or competition with other firms, suppliers and customers, as well as government agencies. On their corporate websites many businesses include links to related stakeholders, which may prove helpful in mapping entire supply chains. It may thus be possible to augment manual methods of cluster research in some way by finding digital evidence of trades in goods or knowledge via the Internet. However, the reality of such an undertaking, on a scale large enough to be both statistically significant and geographically interesting, is non-trivial and rudimentary attempts to scope the effort required have indicated that there are significant problems, some of which may be intractable at the present time. Finally, the methodology presented could be extended to include a longitudinal analysis of cluster evolution and a hierarchical categorisation of clusters.

\section{References}

[1] J.S. Engel, Global Clusters of Innovation: Entrepreneurial Engines of Economic Growth around the World, in, Edward Elgar, Cheltenham, 2014.

[2] S. Breschi, F. Malerba, Clusters, Networks and Innovation, in, Oxford University Press, Oxford, 2005.

[3] E. Carayannis, D.G. Assimakopoulos, M. Kondo, Innovation Networks and Knowledge Clusters, in, Palgrave, New York, 2008.

[4] M. Kenney, R. Florida, Locating Global Advantage, in, Stanford University Press, Stanford, CA, 2004.

[5] C.M. Lee, W. Miller, M.G. Hancock, H.S. Rowen, The Silicon Valley Edge: A Habitat for Innovation and Entrepreneurship, in, Stanford University Press, Stanford, 2000.

[6] M.E. Porter, The Competitive Advantage of Nations, Free Press, New York, 1990.

[7] M.E. Porter, Clusters and competition: new agendas of companies, government and institutions., in: On Competition, Harvard Business School Press, Boston, MA, 1998.

[8] A. Saxenian, Regional Advantage. Culture and Competition in Silicon Valley and Route 128, Harvard University Press, Boston, MA, 1994.

[9] A. Saxenian, The new Argonauts: Regional advantage in a global economy, Harvard University Press, Boston, 2006.

[10] M.A. Waller, S.E. Fawcett, Data science, predictive analytics, and big data: a revolution that will transform supply chain design and management. , Journal of Business Logistics, 34 (2013) 77-84.

[11] G. Wang, A. Gunasekaran, E.W.T. Ngai, T. Papadopoulos, Big data analytics in logistics and 
supply chain management: Certain investigations for research and applications, International Journal of Production Economics, 176 (2016) 98-110.

[12] D.G. Assimakopoulos, I. Oshri, K. Pandza, Management of Emerging Technologies for Socio-Economic Impact, in, Edward Elgar, Cheltenham, 2015.

[13] S. Carmi, S. Havlin, S. Kirkpatrick, Y. Shavitt, E. Shir, . , A model of internet topology using k-shell decomposition., Proc. Natl. Acad. Sci. , 104, (2007) 11150-11154.

[14] R. Catini, D. Karamshuk, O. Penner, M. Riccaboni, Identifying geographic clusters: a network analytic approach, Research Policy, 44 (2015) 1749-1762.

[15] M.P. Feldman, J. Francis, J. Bercovitz, Creating a cluster while building a firm: entrepreneurs and the formation of industrial clusters, Regional Studies, 39 (2005) 129-141.

[16] J. Williams, D.G. Assimakopoulos, Discerning Industrial Networks, Clusters and Competences, in: L.M. Camarinha - Matos (Ed.) Collaborative Networks for a Sustainable World, Springer, New York, 2010.

[17] S. Chakrabarti, B. Dom, A. R., P. Raghavan, Scalable feature selection, classification and signature generation for organizing large text databases into hierarchical topic taxonomies, VLDB Journal, 7 (1998) 163-178.

[18] S. Chakrabarti, M. Van den Berg, D. B., Focused crawling: a new approach to topic specific web resource discovery, Computer Networks and ISDN Systems, 31 (1999) 1623-1640.

[19] H. Chen, Y.-M. Chung, M. Ramsey, C.C. Yang, A smart itsy bitsy spider for the web, Journal of the American Society for Information Science and Technology, 49 (1998) 604-618.

[20] J.M. Pierre, On the automated classification of web sites, Linkoping Electronic Articles in Computer and Information Science, 6 (2001) No 0.

[21] J.M. Pierre, Mining knowledge from text collections' using automatically generated metadata, in: D. Karagiannis, U. Reimer (Eds.) Practical Aspects of Knowledge Management, Springer, Berlin, 2002, pp. 537-548.

[22] S. Benati, S. Garcío, A mixed integer linear model for clustering with variable selection, Computers \& Operations Research, 43 (2014) 280-285.

[23] N. Krislock, V. Mahajan, J. Malick, F. Frédéric Roupin, Computational results of a semidefinite branch-and-bound algorithm for k-cluster, Computers \& Operations Research, 66 153-159.

[24] A. Marshall, Principles of Economics, Macmillan, London, 1920.

[25] F. Perroux, Economic space: theory and applications, The Quarterly Journal of Economics, 64 (1950) 89-104.

[26] A. Weber, Theory of the Location of Industries, in, University of Chicago Press, Chicago, 1929.

[27] D. Ernst, L. Kim, Global production networks, knowledge diffusion and local capability formation, Research Policy, 31 (2002) 1417-1429.

[28] R.A. Boschma, K. Frenken, Why is economic geography not an evolutionary science?, Journal of Economic Geography, 6 (2006).

[29] M. Fransman, The new ICT Ecosystem: Implications for policy and regulations, Cambridge University Press., Cambridge, 2008.

[30] R. Martin, P. Sunley, Deconstructing clusters: chaotic concept or policy panacea?, Journal of Economic Geography, 3 (2003) 5-35.

[31] H. Bathelt, A. Malmberg, P. Maskell, Clusters and knowledge: local buzz, global pipelines and the process of knowledge creation, Progress in Human Geography, 28 (2004) 31-56.

[32] G.A. Carlino, Increasing returns to scale in metropolitan manufacturing, Journal of Regional Science, 19 (1979).

[33] S.A. Rosenfeld, Bringing business clusters into the mainstream of economic development, European Planning Studies, 5 (1997). 
[34] H.D. Rozenfeld, D. Rybski, X. Gabaix, M.H. A., The area and population of cities, The American Economic Review, 101 (2011).

[35] D. Charles, P. Benneworth, Are we realizing our potential?, Regional Studies, 35 (2001) 73-79.

[36] d.P. Hertog, R. Bilderbeek, Conceptualising Service Innovation and Service Innovation Patterns, in: Thematic essay within the framework of the 'Strategic Information Provision on Innovation and Services' (SIID), Ministry of Economic Affairs, 1999.

[37] P. Miller, R. Botham, R. Martin, B. Moore, Business Clusters in the UK - A First Assessment, in, Department of Trade and Industry (DTI), London, 2001.

[38] E.M. Bergman, E.J. Feser, Innovation System Effects on Technological Adoption in a Regional Value Chain, European Planning Studies, 9 (2001).

[39] E.J. Feser, E.M. Bergman, National industry cluster templates: a framework for applied regional cluster analysis, Regional Studies, 34 (2000) 1-19.

[40] M.J. Piore, C.F. Sabel, The Second Industrial Divide, Basic books, New York, 1984.

[41] D. Boyd, K. Crawford, CRITICAL QUESTIONS FOR BIG DATA, Information, Communication \& Society, 15 (2012) 662-679.

[42] M. Graham, T. Shelton, Geography and the future of big data, big data and the future of geography, Dialogues in Human Geography, 3 (2013) 255-261.

[43] R. Cooley, B. Mobasher, J. Srivastava, Web mining: information and pattern discovery on the World Wide Web, in: Proceedings Ninth IEEE International Conference on Tools with Artificial Intelligence, 1997, pp. 558-567.

[44] H. Chen, M. Chau, Web mining: Machine learning for web applications, Annual Review of Information Science and Technology, 38 (2004) 289-329.

[45] D. Corpakis, Spreading Excellence and widening participation under Horizon 2020, in, 2014, pp. 00-16.

[46] D. Foray, J. Goddard, X.G. Beldarrain, M. Landabaso, P. McCann, K. Morgan, C. Nauwelaers, R. Ortega-Argilés, Guide to research and innovation strategies for smart specialisation in: Regional Policy, European Union, 2012.

[47] M. Thelwall, L. Vaughan, L. Björneborn, Webometrics, Annual Review of Information Science and Technology, 39 (2005) 81-135.

[48] M.F. Porter, An algorithm for suffix stripping, Program, 14 (1980) 130-137.

[49] T.L. Griffiths, M. Steyvers, Finding scientific topics., in, National Academy of Sciences, 2004, pp. 5228-5235.

[50] O. Patterson, J.F. Hurdle, Document clustering of clinical narratives: a systematic study of clinical sublanguages., in: AMIA Annual Symposium American Medical Informatics Association, 2011, pp. 1099.

[51] D.M. Blei, A.Y. Ng, M.I. Jordan, Latent dirichlet allocation, Journal of machine Learning research, (2003) 993-1022.

[52] Y. Zhao, G. Karypis, U. Fayyad, Hierarchical clustering algorithms for document datasets. , Data mining and knowledge discovery, 10 (2005) 141-168.

[53] L. Rokach, O. Maimon, Clustering methods in: L. Rokach, O. Maimon (Eds.) Data mining and knowledge discovery handbook, Springer US, 2005.

[54] P. Willett, Recent trends in hierarchic document clustering: a critical review., Information Processing \& Management, 24 (1988) 577-597.

[55] A. Hotho, A. Maedche, S. Staab, (4), . Ontology-based text document clustering, KÜNSTLICHE INTELLIGENZ, 16 (2002) 48-54.

[56] L. Jing, L. Zhou, M.K. Ng, J.Z. Huang, Ontology-based distance measure for text clustering, in: SIAM SDM workshop on text mining, Bethesda, Maryland, USA., 2006. 
[57] Jing L., Ng M.K., Xu J., H.J.Z. In:, Subspace Clustering of Text Documents with Feature Weighting K-Means Algorithm, in: Ho T.B., Cheung D., L.H. (eds) (Eds.) Advances in Knowledge Discovery and Data Mining. PAKDD 2005. Lecture Notes in Computer Science., Springer, Berlin, Heidelberg, 2005.

[58] S. Zhong, Efficient online spherical k-means clustering, in: Proceedings. 2005 IEEE International Joint Conference on Neural Networks, 2005., 2005, pp. 3180-3185 vol. 3185.

[59] R.C. Balabantaray, C. Sarma, M. Jha, Document clustering using K-means and K-medoids., in, arXiv preprint arXiv:1502.07938, 2015.

[60] X. Wang, A. McCallum, Topics over time: a non-Markov continuous-time model of topical trends, in: 12th ACM SIGKDD international conference on Knowledge discovery and data mining, 2006, pp. 424-433

[61] S. Tirunillai, G.J. Tellis, Extracting Dimensions of Consumer Satisfaction with Quality from Online Chatter: Strategic Brand Analysis of Big Data Using Latent Dirichlet Allocation., in, 2014.

[62] K.H. Tan, Y. Zhan, G. Ji, F. Ye, C. Chang, Harvesting big data to enhance supply chain innovation capabilities: An analytic infrastructure based on deduction graph, International Journal of Production Economics, 165 (2015) 223-233.

[63] B.B. Flynn, B. Huo, X. Zhao, The impact of supply chain integration on performance: A contingency and configuration approach. , Journal of operations management, 28(1), (2010) 58-71.

[64] T.G. Bosona, G. Gebresenbet, Cluster building and logistics network integration of local food supply chain. , Biosystems engineering, 108 (2011) 293-302.

[65] P. Lefebvre, Organising Deliberate Innovation in Knowledge Clusters: from Accidental Brokering to Purposeful Brokering processes. , International Journal of Technology Management, 63 (2013) 212-243.

[66] R.N. Anthony, Planning and Control Systems: A Framework for Analysis, Harvard University Press, Cambridge 1965.

[67] D.J. Power, 'Big Data' Decision Making Use Cases, in: B. Delibašić, E.J. Hernández, J. Papathanasiou, F. Dargam, P. Zaraté, R. Ribeiro, S. Liu, I. Linden (Eds.) Decision Support Systems V - Big Data Analytics for Decision Making: First International Conference, ICDSST 2015, Belgrade, Serbia, May 27-29, 2015, Proceedings, Springer International Publishing, Cham, 2015, pp. 1-9.

[68] B.S. Sahay Jayanthi Ranjan, Real time business intelligence in supply chain analytics, Information Management \& Computer Security, 16 (2008) 28-48.

[69] L.J. Spence, L. Rinaldi, Governmentality in accounting and accountability: A case study of embedding sustainability in a supply chain, Accounting, Organizations and Society, 39 (2014) 433-452.

[70] B.T. Hazen, J.B. Skipper, C.A. Boone, R.R. Hill, Back in business: operations research in support of big data analytics for operations and supply chain management, Annals of Operations Research, (2016) 1-11. 